\title{
Influence of Social Networks on Family Planning Use among Married Men and Women: A Case of Mvomero District, Tanzania
}

\author{
Harrieth G. Mtae, PhD \\ The Open University of Tanzania \\ Corresponding Mail: harrieth.mtae@out.ac.tz
}

\begin{abstract}
This paper was about the influence of social network on family planning (FP use among married men and women) in Mvomero District of Morogoro Region. The study employed the cross section study design, involving 128 married men and women. The choice of respondents was done through multistage sampling which involved purposive and simple random sampling techniques. Interview and focus group discussions were used as the methods of data collection. Quantitative data was collected using semi structured questionnaire and qualitative data were collected using FGDs guide and key informant interview guide. Quantitative data was analysed using descriptive statistics. The findings reveal that majority of married men and women in Mvomero were still young, having at least a primary school education and in monogamous marriage. Nearly one third of them were not using any FP methods and of the methods used, pills and injectables dominated. Most married men and women had social networks of both males and females, though most married women had more females and married men had more males in their networks. Further, Married women tended to discuss more on FP use with their social networks than married men (especially pills and injectables). However, nearly all social network members encouraged married men and women to use family planning which is a commendable thing to do. It is therefore recommended that interventions targeting to increase FP information and therefore use among married men and women through social networks should be designed and implemented targeting both females and males. There is also a need to encourage men to participate fully in FP, reproductive and health issues as in most of the households in Tanzania, they are the decision makers. It is expected that through their participation, they will support and encourage their partners to use FP methods.
\end{abstract}

Keywords: Social networks, family planning, family planning methods, family size

\section{Introduction}

Rates of family planning usage vary globally. United Nations reported that a mean of $64 \%$ of married or in-union women of reproductive age use some form of family planning and the rates were highest (75\%) in North America and lowest (33\%) in Africa (UN 2015). The UN further identified that around one in ten married or in-union women worldwide were estimated to have an unmet need for family planning, especially among adolescents because contraception use and adherence in this age group varies (UN 2015). Resolving this unmet need for contraception is a vital global public health concern (Alkema, Kantorova, Menozzi and Biddlecom, 2013; Gold, et al. 2011).
It is very important to know what makes married men and women use or not to use FP methods and to have the family size that they have, especially in Tanzania where fertility rates are considerably high just like many of the developing countries. Individuals have the right to decide freely and responsibly on the use of FP methods (when to have the children and how to space them) as well as the number of children to have. Nonetheless, there are only a small proportion of women in Africa who want to space or limit their pregnancies and yet are not using any form of FP method (USAID, 2007; Ernest et al., 2011). Demographers and health specialists refer to these women as having an "unmet need" for FP - a concept that has influenced the development of family planning programs for 
more than two decades. In Africa, besides this, about 17 percent of all married women would prefer to avoid a pregnancy but are not using any form of FP (UN, 2008).

Agwanda and Amani (2014) reported that, Tanzania is one of the first countries in Sub-Saharan Africa to establish FP program in 1959 but its contraceptive prevalence rate is 34 percent. They further stated that Tanzania continues to experience high fertility rates and desire for large family size and unchanging unmet needs for contraception. Furthermore, in Tanzania, the highest unmet need is among rural dwellers with no education (30\%) and (24.6\%) of those with primary education (Agwanda and Amani, 2014).

One of the central questions in population policy has been the extent of unintended fertility and correspondingly, the amount of unsatisfied demand for fertility regulation. An estimated 2.9 million unintended pregnancies could be averted over the next decade if the unmet need for contraception were met (URT, 2010). Many married men and women in Tanzania are likely not to make the right decisions on FP use and its consequences includes high fertility rates. Researches has reported the association between high fertility rate and low use of contraceptives, high infant mortality rates, under five mortality rates and maternal mortality rates which is also the case in Tanzania (DaVanzo, Hale, et al. 2008; Yeakey, et al. 2009; DHS, 2010; Ahmed, et al., 2012).

A lot of effort has been made to promote the use of FP and the importance of having small family size by using mass media like televisions, radio, newspapers, drama and other programs such as antenatal clinics for pregnant women (URT, 2010). In spite of all these efforts, many married men and women in Mvomero are still not in a position to make right decisions on FP and so resulting into high fertility rates.

Family, friends and neighbors are examples of typical social networks. Others include women's groups, political, church or youth associations, mutual aid and credit groups and marketing associations. Individuals make decisions not in social isolation but in interaction with other people. Some experts believe that many individuals feel uncertain about the health, social and economic consequences of using modern contraceptives and this uncertainty often leads people to discuss matters with their peers, to seek more information or just to be reassured about decisions to begin using contraception (Sharan \& Valente, 2002). Contraception is a key public health intervention to prevent unintended pregnancy. According to Cleland et al. (2012), unintended pregnancy is common globally and has negative health consequences for both women and children.

A study conducted in India by Rustagi et al., (2010) reported that participants were more inclined to pressure from family members in having more children. In this regard, social influence points at the importance of authority and social conformity pressures that exist in some societies which in turn maintain existing social norms, but constrains innovative behavior. Literature shows that, decisions regarding fertility and childbearing are largely the domain of older female relatives. However, a study by Coleran and Mace (2015) found little evidence that kin directly influence contraceptive uptake, either by their presence/absence or as models for social learning. Therefore, the intention of this study was to find out whether social network is by any means playing a part in influencing married men and women on the use of family planning in Mvomero District and therefore respond to the general research question which was, is there a link between social network and contraceptive use among married men and women in Mvomero District? Specific research questions were two:

1. What are the characteristic of married men and women in Mvomero District?

2. Who are the social network members and their influence in family planning use in Mvomero District?

\section{Research Methodology}

This section presents the methodology used in this study including the research design, population and sampling techniques, description of the study area, data collection methods, validity and reliability of data collecting tools, data collection methods and ethical consideration.

\section{Research Design}

This study employed cross sectional survey which was selected because it is flexible and it focusses on studying and drawing conclusions from existing differences between people, subjects or phenomena. It is also capable of using data from a large number of subjects and, unlike observational studies, it is relatively inexpensive and takes up short time to conduct. 


\section{Population and Sampling Techniques}

The population for this study was married men and women in the households in Mvomero District. The term "married" refers to legal or formal marriage, while "living together" designates an informal union in which a man and a woman live together, even if a formal civil or religious ceremony has not occurred. In this study, these two categories were considered as married. The other condition was to have at least one biological child and if a married woman must have age range of 15 to 49 years and if a married man should be between 15 and 64 years of age. The choice of married men and women was based on the fact that they are considered to be more active sexually than other groups and therefore more likely to engage in FP especially after getting their first child. Individuals dealing with reproductive matters in the District, District Reproductive and Child Health Officers (DRCHO) and elders (male and female) were also interviewed in order to get more information regarding family planning.

The sample size required for the study was 328 which was obtained based on the assumed proportion of women aged 15 to 49 years $(80,959)$ and men aged 15 to 64years $(72,143)$ in Mvomero, making a total of 153, 102 (URT, 2010). Sample size was determined by the following formula given by Kothari, (2006).

\section{$Z^{2} \varnothing P^{2} N$}

$$
\mathrm{n}=(\mathrm{N}-1)\left(\mathrm{e}^{2}\right)+\mathrm{Z}^{2} \emptyset \mathrm{P}^{2}
$$

\section{Where:}

$\mathrm{n}=$ Required sample size of the study population

$\mathrm{N}=$ Size of the Universe population of the community studied

$\varnothing \mathrm{P}=$ Assumed standard deviation of the studied population $=2.15$

$\mathrm{e}=$ Acceptance error for the whole estimation $=0.5$

$\mathrm{Z}=$ Table value under normal curve for the given confidence level of $95 \%$

A multistage sampling technique and purposive sampling were employed in order to get representative sample.

\section{Multistage Sampling}

Multistage sampling refers to sampling plans where the sampling is carried out in stages using smaller sampling units at each stage. It is a sampling method in which larger clusters are further subdivided into smaller, more targeted groupings for the purposes of surveying (Kaplan, 2013). It included both, purposive sampling and simple random sampling.

Purposive sampling is a form of non-probability sampling in which decisions concerning the individuals to be included in the sample are taken by the researcher, based upon a variety of criteria which may include specialist knowledge of the researched issue or capacity and willingness to participate in the research (Jupp, 2006).

This sampling method was used in order to capture qualified study area and respondents and specifically it was used to select a representative district from Morogoro region, one of the regions with higher contraceptive prevalence (URT, 2010). It was also used in selection of married men aged 15 to 64 years and women aged 15 to 49 years with at least one child of their own. Key informants included DRCHO, two elders (a male and female) from each selected ward and three religious leaders.

simple random sampling is the basic sampling technique whereby the researcher selects a group of subjects (a sample) for study from a larger group (a population). Each individual is chosen entirely by chance and each member of the population has an equal chance of being included in the sample (probability sampling). Every possible sample of a given size has the same chance of selection (Garson, 2012). Simple random sampling was used to select four wards of Mvomero Districts and two villages as well as selection of twenty households where married men and women lived (whether married or living together and with one child) from the list provided by the village/hamlet executive officer (VEO). As Taherdoost (2016) asserted, there is an equal chance of selection for each member of the population in random sampling. The sampling frame for this study was the villages register from VEOs office.

\section{Description of the Study Area}

Mvomero District is one of the five districts in Morogoro Region. It was created by splitting the former Morogoro District and the District was formally gazetted on 17th September 2004 through the Government Notice Number 453. The name 'Mvomero' was taken from the name of the famous Mvomero River, which passes through Mvomero village in the District. The name Mvomero originated from the Luguru word vomea, which means 'to sink.'

According to the 2012 Population and Housing Census, the population of Mvomero District was 
312,109 of which 154,843 were males and 157,266 were females with average household size of 4.3 and an average population growth rate of 2.6 percent which is slightly lower than the national average of $2.7 \%$. The district is administratively divided into four divisions, namely Mgeta, Mvomero, Turiani, and Mlali, which together comprise of 23 wards and 115 villages. The dominant ethnic tribes are Luguru, Kaguru, Nguu and Zigua. There has also been an inflow of other ethnic tribes such as Wakwere, Mang'ati, Wasukuma, Maasai, Barbeig and Pogoro. These groups migrated to Mvomero in search of pastures for their livestock as well as good fertile agricultural valleys for agricultural production.

The economy of the district' depends highly on agriculture, especially from crop production. Food crops produced by the majority include maize, cassava, paddy, pulses, cocoyams and sorghum while the cash crops are mainly sugarcane, simsim, coffee, bananas, sunflower and vegetables. There are also varieties of livestock like beef and dairy cattle, indigenous and dairy goats, sheep and poultry. Crop farming is the major economic activity employing 81.6 percent of the total labour force followed by elementary occupations $(9,992)$, crafts $(2,754)$, Street vendors $(1,901)$ and Livestock keeping $(1,296)$. More than 80 percent of Mvomero adult population earns their livelihood from agriculture though mainly at subsistence level (Morogoro Region Social-economic Profile, 2007).

Mvomero had 43 dispensaries, 35 of which were public and 8 were private (Profile of Morogoro Region, 2007). The three district level hospitals in Mvomero are Mtibwa Sugar Estate Hospital - a private employer's facility, Turiani Hospital - a private religious facility, and Chazi Hospital - a public facility.

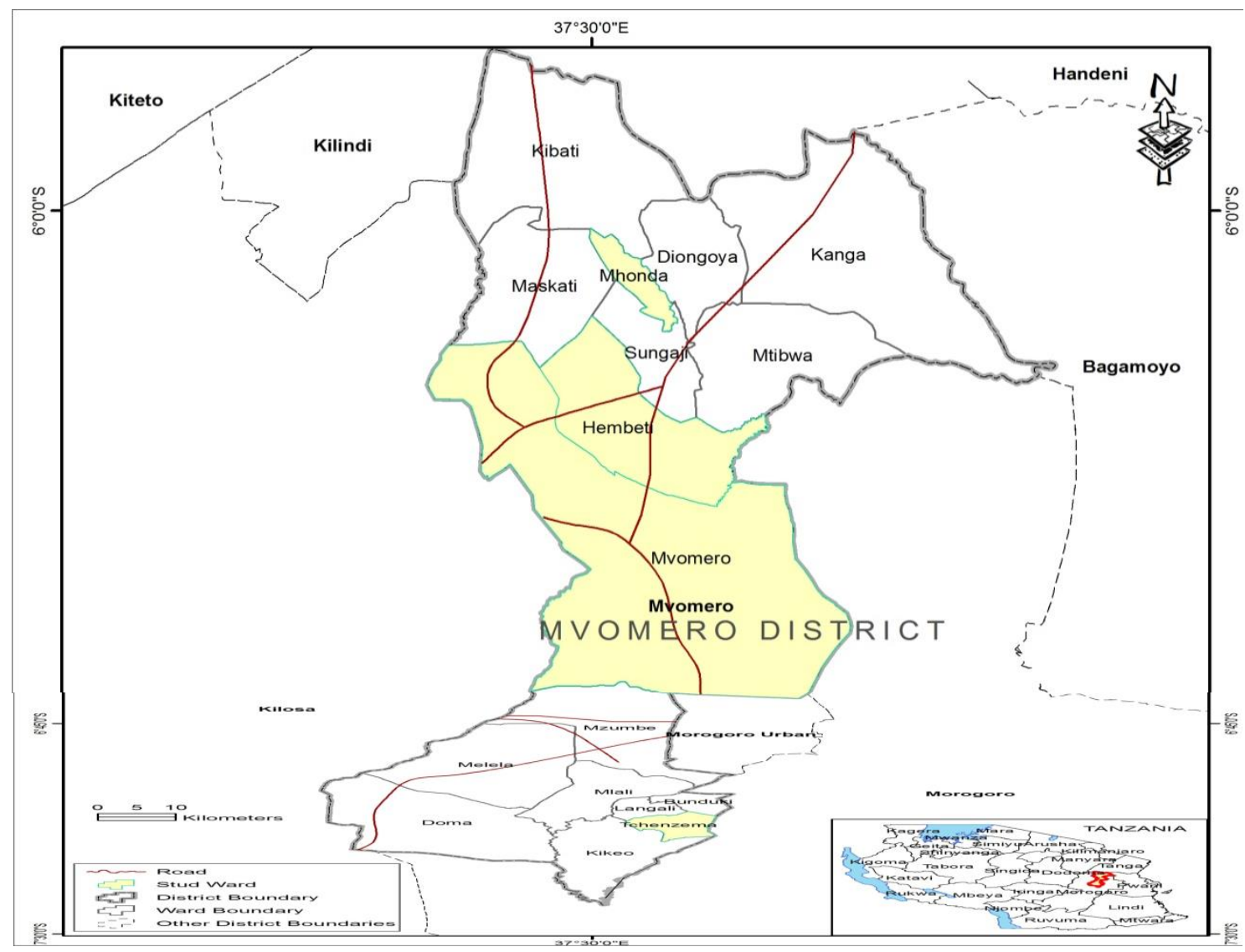

Figure 1: Map of Mvomero District (Source: University of Dar es Salaam, IRA, GSI Lab).

\section{Data Collection Methods}

The study employed both primary and secondary data as main sources of information. Primary data were collected at the field and its collection involved structured interview, focus group discussion and key informant interviews. Secondary data were obtained from both published and unpublished 
reports on FP issues for a better understanding of the study and what have been done by others.

\section{Validity and Reliability}

To ensure validity and reliability, the researcher pretested 20 questionnaires to the respondents with similar characteristics in Tchenzema Ward to targeted population of this study. The questionnaire was then edited and corrected as necessary. Reliability is concerned with the ability of an instrument to measure consistently, and test retest method was used to ensure its validity. It should be noted that the reliability of an instrument is closely associated with its validity (Tavacol \& Dennick et al., 2011).

\section{Statistical Treatment of Data}

The activity of data compilation and processing started immediately after the end of the major field work. The questionnaires' were manually edited, coded and then data entry and processing was done using SPSS Version 20. Entered data were cleaned for validation and consistency. Thematic analysis was employed to analyze data emanating from Focus Group Discussions and interviews from elders and DRHCOs. The collected information was analyzed by themes and verbatim quotations were used to illustrate responses on relevant issues and themes. Detailed notes were taken and discussion was audio taped for easy reference in the future. Each FGD outcome was summarized and used to supplement the quantitative information.

\section{Ethical Considerations}

Privacy and confidentiality were observed and research clearance was sought at all levels. Prior to interview, the researcher and research assistants asked for individual's consent and the objectives of the research was explained to prospective respondents. Those who were not ready to be interviewed for one reason or another were excused from the study. As the research involved married men and married women, the interview was conducted separately in order to ensure confidentiality, thus maximum freedom of expression of ideas from both groups.

\section{Results and Discussions}

This section presents the findings of the study based on the two research questions.

\section{Respondents Characteristics}

In order to answer the first question which was, what are the characteristic of married men and women in Mvomero District?, it was important to know the age, marital status, education and the current contraceptive use status of the respondents. In table 1 , majority of married women (50\%) and men (38.4\%) were aged between 25 and 34. Women at the age of 15 to 49 years and men at the age of 15 to 64 are still fertile and are capable of giving birth in the future if they will not control their fertility.

Table 1: Respondents Characteristics (\%)

\begin{tabular}{|c|c|c|}
\hline Category & Married Women & Married men \\
\hline \multicolumn{3}{|l|}{ Age } \\
\hline $15-24$ & 18.9 & 06.7 \\
\hline $25-34$ & 50.0 & 38.4 \\
\hline $35-44$ & 23.2 & 24.4 \\
\hline $45-54$ & 07.9 & 26.2 \\
\hline $55-64$ & - & 04.2 \\
\hline \multicolumn{3}{|l|}{ Marital status } \\
\hline Monogamous & 97.6 & 97.0 \\
\hline Polygamous & 02.4 & 03.0 \\
\hline \multicolumn{3}{|l|}{ Education } \\
\hline Incomplete primary school & 06.9 & 08.3 \\
\hline Complete primary school & 81.9 & 80.8 \\
\hline Incomplete secondary school & 08.3 & 01.9 \\
\hline Complete secondary school & 02.8 & 08.3 \\
\hline Higher than secondary school & - & 00.6 \\
\hline $\mathrm{N}$ & 144 & 156 \\
\hline
\end{tabular}

Based on the findings by American Society for Reproductive Medicine, (2012), best reproductive years for woman are in their twenties and their fertility slowly declines in their thirties, especially after reaching thirty five years. Monogamous was reported by $97.6 \%$ of married women and $97 \%$ of married men. This could be an indication that some few married women think they are in a 
monogamous marriage while they are not. The study further explored the levels of education married men and women attained. It was revealed that majority of married women completed primary school education level (81.9\%) and married men were $80.8 \%$. It is reported by Adeyoju (2013) in a study conducted in Nigeria that in comparison to men who have no education, men with primary education were four times likely to use modern contraceptives and men who have reached secondary and higher education are eight times more likely to use family planning methods.

\section{Current Contraceptive Use}

One of the indicators most frequently used to assess the success of FP activities is the level of current family planning use. To get this information, married women and men were asked whether they are currently using any family planning method. Findings revealed that more married women are using contraceptives than married men. However majority of respondents reported not to use any of the family planning methods as in Table 2

Table 2: Current Family Planning Use

\begin{tabular}{lccc}
\hline Family planning Method & Married Women & Married men & Total \\
\hline F/sterilization & 05.5 & - & 05.5 \\
M/sterilization & - & 01.2 & 01.2 \\
IUD & 0.6 & - & 0.6 \\
Injectables & 28.0 & - & 28.0 \\
Implants & 2.4 & - & 2.4 \\
Pills & 14.6 & - & 14.6 \\
Diaphragm & 3.0 & - & 3.0 \\
Condom & - & 5.5 & 5.5 \\
Foam and jelly & - & - & - \\
Rhythm & 10.4 & - & 10.4 \\
Withdrawal & - & 6.1 & 6.1 \\
Traditional & - & - & - \\
LAM & - & - & - \\
None & 32.3 & 26.2 & 58.5 \\
\hline
\end{tabular}

Table 3: Social Network Members (\%)

\begin{tabular}{cccc}
\hline Response & Married Women & Married Men & Total \\
\hline Yes & 96.3 & 93.9 & 95.1 \\
No & 03.7 & 06.1 & 04.9 \\
\hline $\mathrm{n}$ & 158 & 154 & 312 \\
\hline
\end{tabular}

\section{Influence of Social Network on Family Planning}

Findings in this section responds to the second question of this study which was who are the social network members and their influence in family planning use in Mvomero District? Findings presented here include on identifying influence mechanisms, network members and discussion on contraceptive use and finally network structure and their modes of action.

\section{Identifying Social Network Members}

Married men and women were asked to mention at least four people - apart from their partners, whose opinion matters and who can discuss personal matters with them like, about number of children to have, children, work, family planning use, church/mosque etc in order to establish social networks and its effect in adoption of contraceptive.
Married women had at least one person other than their husbands from whom they sought opinion $(96.3 \%)$ and for married men it was $93.9 \%$. This is the indication that the remaining portion of respondents did not trust opinions of other people apart from their partners or themselves as indicated in Table 3.

Married men and women were further asked to tell the gender of their four social network members, and it was noted that most married women had more females than males in their social network and for married men their social networks are of more males than females. This signifies that regarding various important issues, women trust their fellow females more than males and men trust their fellow males than females as shown in Table 4. 
Table 4: Gender of Social Network Member

\begin{tabular}{ccccccccc}
\hline Gender & \multicolumn{4}{c}{ Women } & \multicolumn{4}{c}{ Men } \\
& $1^{\text {th }}$ & $2^{\text {nd }}$ & $3^{\text {rd }}$ & $4^{\text {th }}$ & $1^{\text {st }}$ & $2^{\text {nd }}$ & $3^{\text {rd }}$ & $4^{\text {th }}$ \\
\hline Male & 24.1 & 30.1 & 28.6 & 31.7 & 90.3 & 84.8 & 81.4 & 82.3 \\
Female & 75.9 & 69.9 & 71.4 & 68.3 & 09.7 & 15.2 & 18.6 & 17.7 \\
$\mathrm{n}$ & 158 & 143 & 112 & 82 & 154 & 125 & 102 & 62 \\
\hline
\end{tabular}

Table 5: Relationships with Social Network Members

\begin{tabular}{ccccccccc}
\hline Relationship & \multicolumn{4}{c}{ Women } & \multicolumn{4}{c}{ Men } \\
& $1^{\text {th }}$ & $2^{\text {nd }}$ & $3^{\text {rd }}$ & $4^{\text {th }}$ & $1^{\text {st }}$ & $2^{\text {nd }}$ & $3^{\text {rd }}$ & $4^{\text {th }}$ \\
\hline Friend & 18.9 & 11.1 & 16.8 & 10.7 & 46.7 & 43.1 & 41.7 & 50.0 \\
Close relatives & 50.3 & 49.4 & 46.9 & 48.9 & 29.6 & 31.8 & 35.4 & 18.4 \\
Distant relatives & 20.7 & 25.7 & 26.6 & 39.1 & 8.6 & 10.6 & 005.0 & 16.7 \\
Others & 10.1 & 13.9 & 9.7 & 9.5 & 15.2 & 13.8 & 14.5 & 15.0 \\
$\mathrm{n}$ & 159 & 144 & 113 & 84 & 152 & 123 & 96 & 60 \\
\hline
\end{tabular}

Table 6: Discussion on FP use in the Past Year

\begin{tabular}{lll}
\hline Response & Married Women & Married Men \\
\hline Yes & 40.2 & 28.7 \\
No & 59.8 & 71.3 \\
$\mathrm{n}$ & 164 & 100 \\
\hline
\end{tabular}

This conforms to what Kodzi (2009) and Mosha and Reuben (2013) reported that men and woman are more likely to adopt the reproductive behavior of other men and women in their social network and their fertility decision would have to include considerations of the desires of their spouse. According to Rossier and Benardi (2010), social interactions tend to influence reproductive and contraceptive behavior through social learning and social influence processes. This means men and women do discuss on FP use at individual level or in groups, but the final decision on which method someone is going to use depends on spousal consent among others.

\section{Identifying Influence Mechanisms}

In order to get more information on married women's social network, interviewees were asked to provide information on the kind of relationship they have with their four social network members. Though a wide range of relationship was reported, about a half of the respondents reported to trust more their close relatives (fathers, mothers, sisters, brothers, daughters and sons) followed by distant relatives (in laws, grandparents, nephews, aunts and uncles) as shown in Table 5.

These results are an indication that apart from their husbands, women tend to trust more and seek advice from their close relatives and distant relatives before talking to their friends. The least reported group was others (neighbors, pastors, sheikhs and nurses).
As for men, friends and close relatives were highest among those reported to be people whose opinion matters to interviewees other than their wives. This is an indication that men unlike women, tend to seek advice on various important issues from their friends first before turning to their close relatives as in Table 3. During FDGs, it was reported that apart from getting advices from family members, discussion on various issues including FP take place with other community members especially when the family is too big. The discussion among social network members would dwell sometimes on issues related to family size, especially advising a man either to separate with her partner for a while. One married man had reported that:

\section{Sometimes you may find a woman giving birth to many children continuously to the extent that it is threatening her life, so a man could be advised to leave her and get married to someone else for his wife to get some time to rest (managed 54yrs).}

Normally these kinds of conversations take place when drinking or selling booz, when working, when visiting each other or when they meet accidentally on the road but this occur mostly to peers or people who know and trust each other well.

\section{Network Members and Discussions on FP Methods}

Findings show that in the past year $40.2 \%$ of married women discussed about family planning while only $28.7 \%$ of married men did the same as in Table 6 . 
This means that, though most married men and women have social networks, married men tended to discuss other issues more apart from FP as compared to women. These findings are supported by Colleran and Mace (2015) who reported that a strong correlated contraceptive behavior among friends and families may indicate a frequencydependent probability of contraceptive use, whereby women adopt the contraceptive behavior (and by proxy the reproductive norms) of their preferred social models as they become more frequent in their social networks.

Report by Avogo et al., (2008) suggested that social networks, particularly men's networks may start out as conservative and dismissive of the idea of controlling childbearing but as new ideas emerge about the benefits of having fewer children, these networks may spread information and help to transmit ideals about smaller family sizes, thereby leading to the adjustment of couple's fertility intentions. During focus group discussions, married women agreed that there is existence of social networks and they do discuss various issues regardless of the place when two or three people meet, could be when they watch or play football, in places where people meet and discuss issue in order to pass time and when visiting each other. Some married respondents had different opinion: "Many women do not trust each other to the extent of discussing family planning issues. Their worry is, the person she is discussing with can go and tell her husband about it and this can result to a conflict or divorce" (Married woman aged 45yrs).

Those who reported to have discussed about contraceptive use in the last twelve months were more comfortable to discuss issues related to FP Method use with their friends and close relatives. Married women reported to discuss mostly with close relatives, followed by friends. For men, majority reported to discuss about FP method mostly with their friends than the rest as in Table 7. This means married men trust friends more in discussion about matters related to FP method use than the rest of social network members. This was supported by one married man who reported that:
Discussion about family planning though
it is not very common, when we do, we discuss family planning methods mostly used by women not by men.... and there is no specific place for such discussions it just happen when we meet with other men so long as there is privacy and trust (Married man aged 50yrs).

Table 7: Relationship with Social Network Member who discussed FP with

\begin{tabular}{|c|c|c|c|c|c|c|c|c|}
\hline \multirow[t]{2}{*}{ Relationship } & \multicolumn{4}{|c|}{ Women } & \multicolumn{4}{|c|}{ Men } \\
\hline & $1^{\text {th }}$ & $2^{\text {nd }}$ & $3^{\text {rd }}$ & $4^{\text {th }}$ & $1^{\text {st }}$ & $2^{\text {nd }}$ & $3^{\text {rd }}$ & $4^{\text {th }}$ \\
\hline Friend & 34.8 & 25.0 & 50.0 & 53.8 & 68.0 & 67.7 & 64.3 & 62.5 \\
\hline Close relatives & 40.9 & 45.0 & 40.9 & 38.5 & 10.0 & 06.5 & 7.1 & 25.0 \\
\hline Distant relatives & 12.1 & 12.5 & - & 07.7 & 12.0 & 9.7 & 28.6 & - \\
\hline Others & 12.1 & 17.5 & 09.1 & - & 13.2 & 13.0 & - & 12.5 \\
\hline $\mathrm{n}$ & 66 & 40 & 22 & 13 & 25.0 & 29 & 16 & 08 \\
\hline
\end{tabular}

Table 8: Encouragement on the use of FP by Social Network

\begin{tabular}{lllllllll}
\hline Response & \multicolumn{7}{l}{ Women } & \multicolumn{7}{c}{ Men } \\
\cline { 2 - 8 } & $1^{\text {th }}$ & $2^{\text {nd }}$ & $3^{\text {rd }}$ & $4^{\text {th }}$ & $1^{\text {st }}$ & $2^{\text {nd }}$ & $3^{\text {rd }}$ & $4^{\text {th }}$ \\
\hline Encourage & 100.0 & 100.0 & 100.0 & 100.0 & 95.7 & 93.3 & 92.9 & 85.7 \\
Discourage & - & - & - & - & 4.3 & 6.7 & 7.1 & 14.3 \\
\hline $\mathrm{n}$ & 67 & 40 & 22 & 12 & 47 & 30 & 14 & 07 \\
\hline
\end{tabular}

It was also important to find out whether there was discouragement or encouragement to use FP methods during the discussion among network members. Based on the findings, majority of social network members encouraged both married women and men respondents to use FP. This is an indication that the decision to use family planning for both married men and women is sometimes influenced by social network members who themselves use family planning and those who accept the use of family planning use (Table 8).

This is supported by Sarfraz et al, (2021) who reported that majority of respondents stated that their source of information about contraceptives in general, were predominantly from female relatives (mothers, sisters, aunts, cousins) who have also used contraceptive methods, mostly IUCDs. It seems a common practice, even normative, for married 
women to share their experiences of contraceptives with other women in their relatives' network.

According to Avogo and Agadijanan (2008), the encouragement received by men influences subsequent contraceptive adoption only through spousal interaction, while the latter encouragement received by women affects contraception adoption both through spousal interaction and directly to individual women. Among the discussed family planning methods, pills and injectables were discussed more with both married men and women as in Table 9. Generally, male sterilization, withdrawal and traditional methods were not discussed by married women while IUD, Diaphragm and traditional methods were not discussed at all with married men as in Table 9.

The theory of social network recognizes that as individuals interact, they learn and get information from each other. It is, expected that discussions on family planning matters among social network members can have influence on individuals' attitude towards family planning and, it is easier for non-user of family planning to be influenced by users. According to Yee and Simon (2010), rumors, myths and vicarious experiences supplied by the social network had a direct impact on contraceptive decisions for a number of women as some reject an effective contraceptive method available to them entirely because of a myth relayed through their social network. The prominent myths and misconceptions were largely focused on issues of safety, efficacy and side effects of methods. Skepticism about method efficacy, often with stories of failed contraception use and fear of side effects were pervasive. On the more encouraging side, however, some women chose a method specifically because of the positive experience of their friends and family.

Table 9: Discussed FP

\begin{tabular}{lllllllll}
\hline FP Method & \multicolumn{7}{l}{ Women } & \multicolumn{7}{l}{ Men } \\
\cline { 2 - 9 } & $1^{\text {th }}$ & $2^{\text {nd }}$ & $3^{\text {rd }}$ & $4^{\text {th }}$ & $1^{\text {st }}$ & $2^{\text {nd }}$ & $3^{\text {rd }}$ & $4^{\text {th }}$ \\
\hline F/sterilization & 03.0 & - & - & - & 06.4 & 3.6 & - & - \\
M/sterilization & - & - & - & - & 04.3 & 3.6 & - & - \\
IUD & 06.0 & 02.5 & 13.6 & 08.3 & - & - & - & - \\
Injectables & 55.2 & 52.5 & 54.5 & 41.7 & 36.2 & 32.1 & 57.1 & 3.0 \\
Implants & 04.5 & - & - & 08.3 & 04.3 & 14.3 & 7.1 & - \\
Pills & 22.4 & 42.5 & 04.5 & 25.0 & 27.7 & 21.4 & 28.6 & 0.6 \\
Condom & 03.0 & - & 22.7 & 08.3 & 06.4 & 10.7 & - & 0.6 \\
Diaphragm & 03.0 & - & 04.5 & - & - & - & - & - \\
Rhythm & 03.0 & 02.5 & - & - & 06.4 & 3.6 & - & - \\
Withdrawal & - & - & - & - & 08.5 & 10.7 & 7.1 & 95.7 \\
Traditional & - & - & - & - & - & - & - & - \\
\hline $\mathrm{n}$ & 67 & 40 & 22 & 12 & 47 & 28 & 14 & 28 \\
\hline
\end{tabular}

Table 10: Who Initiated Discussion on Contraceptive Use

\begin{tabular}{ccccccccc}
\hline \multirow{2}{*}{ Response } & \multicolumn{6}{c}{ Women } & \multicolumn{5}{c}{ Men } \\
\cline { 2 - 9 } & $1^{\text {th }}$ & $2^{\text {nd }}$ & $3^{\text {rd }}$ & $4^{\text {th }}$ & $1^{\text {st }}$ & $2^{\text {nd }}$ & $3^{\text {rd }}$ & $4^{\text {th }}$ \\
\hline Respondent & 65.7 & 75.0 & 68.2 & 34.3 & 68.8 & 67.6 & 71.6 & 14.3 \\
Other person & 34.3 & 25.0 & 31.8 & 25.0 & 27.1 & 32.4 & 28.6 & 85.7 \\
\hline $\mathrm{n}$ & 67 & 40 & 22 & 12 & 48 & 34 & 14 & 07 \\
\hline
\end{tabular}

\section{Network Structure and Modes of Action}

Interviewees were asked to give information on who initiated discussions as for a discussion to take place, there must be someone who initiated it. Most married women and married men reported to initiate the discussions themselves as indicated in Table 10.

It was further observed that many FP methods were discussed and were reported to be used. This indicates that both married women and men social networks have influence on FP methods use regardless of whether the respondent is the initiator of the discussion or not, and the most used FP methods reported were pills and injectables as in Table 11. Samandari et al.,(2010) suggests that social support of husbands, peers and elders who reported that their network partners approve FP and encourage them to use were more likely to use FP methods themselves, as the association encouragement and actual use was particularly strong. 
Table 11: Responses on the Type of Contraceptive used (\%)

\begin{tabular}{lllllllll}
\hline FP Method & \multicolumn{7}{l}{ Women } & \multicolumn{7}{l}{ Men } \\
\cline { 2 - 9 } & $1^{\text {th }}$ & $2^{\text {nd }}$ & $3^{\text {rd }}$ & $4^{\text {th }}$ & $1^{\text {st }}$ & $2^{\text {nd }}$ & $3^{\text {rd }}$ & $4^{\text {th }}$ \\
\hline F/sterilization & 03.1 & - & - & - & 04.5 & - & 07.1 & 14.3 \\
M/sterilization & - & 05.0 & - & - & 02.3 & 03.6 & - & - \\
IUD & - & 02.5 & - & - & 02.3 & 03.6 & - & - \\
Injectables & 63.1 & 55.0 & 54.5 & 66.7 & 29.5 & 32.1 & 57.1 & 57.1 \\
Implants & 04.6 & 02.5 & 09.1 & 08.3 & 04.5 & 07.1 & 07.1 & - \\
Pills & 21.5 & 32.5 & 31.8 & 08.3 & 22.7 & 21.4 & 14.3 & - \\
Condom & 01.5 & - & - & 16.7 & 13.6 & 14.3 & 07.1 & 14.3 \\
Diaphragm & 03.1 & - & 04.5 & - & - & - & - & - \\
Rhythm & 03.1 & 02.5 & - & - & 11.4 & 07.1 & - & 14.3 \\
Withdrawal & - & - & - & - & 09.1 & 10.7 & 07.1 & - \\
Traditional & - & - & - & - & - & - & 01.0 & - \\
\hline $\mathrm{n}$ & 65 & 40 & 22 & 12 & 44 & 28 & 14 & 07 \\
\hline
\end{tabular}

Table 12: Social Network Members' Disclosure on Contraceptive Method

\begin{tabular}{ccccccccc}
\hline Response & \multicolumn{4}{c}{ Women } & \multicolumn{4}{c}{ Men } \\
\cline { 2 - 9 } & $1^{\text {th }}$ & $2^{\text {nd }}$ & $3^{\text {rd }}$ & $4^{\text {th }}$ & $1^{\text {st }}$ & $2^{\text {nd }}$ & $3^{\text {rd }}$ & $4^{\text {th }}$ \\
\hline He /She told me & 87.7 & 292.5 & 91.3 & 100.0 & 90.5 & 92.3 & 100.0 & 100.0 \\
l asked him /her & 12.3 & 07.5 & 08.7 & - & 9.5 & 7.7 & - & - \\
\hline $\mathrm{n}$ & 65 & 40 & 23 & 100 & 42 & 26 & 13 & 06 \\
\hline
\end{tabular}

Knowing how both married men and women got to know the type(s) of FP methods their social network members use was very important. Findings reveal that most network members shared with respondents on the specific contraceptives they use without being asked as in Table 12 .

through social networks should be designed and implemented targeting both females and males starting from the age of 15 years regardless of their marital status.

\section{Conclusions and Recommendations}

This part gives the conclusions of the study and then presents the recommendations.

\section{Conclusion}

Majority of married men and women in Mvomero were still young, having at least a primary school education. Nearly one third of them are not using any family planning methods. Of the family planning methods, pills and injectables were the most used.

Most married men and women had social networks of both males and females, though most married women had more females in their networks. Married women tend to discuss more on FP method use with their social networks than married men (especially pills and injectables). However, nearly all social network members encourage married men and women to use FP which is a commendable thing to do.

\section{Recommendations}

Interventions targeting to increase FP information and therefore use among married men and women through social networks should be designed and implemented targeting both females and males starting from the age of 15 years regardless of their marital status.

There is need to Encourage men to participate fully in family planning, reproductive and health issues as in most of the households in Tanzania, they are the decision makers. It is expected that through their participation, they will support and encourage their partners to use FP methods.

\section{Reference}

Adeyoju, T. O., and Ibisomi, L.D. (2013). Fertility intention and contraceptive use among males in Nigeria. Paper presented at the Population Association of America 2013 Annual Meeting Program, New Orleans, LA, Sheraton New Orleans, April 11-13.

Agwanda, A and Amani, H (2014). Population Growth, Structure and Momentum in Tanzania. TDHR 2014. Background Paper No. 7, ESFR Discussion paper 61.

Ahmed S, Li Q, Liu L, Tsui, A (2012). Maternal deaths averted by contraceptive use: an analysis of 172 countries. Lancet. 2012 Jul 14;380(9837):111-25. doi: 10.1016/S0140- 
6736(12)60478-4. Epub 2012 Jul 10. PMID: 22784531.

Alkema L, Kantorova V, Menozzi C, Biddlecom A. (2013). National, regional, and global rates and trends in contraceptive prevalence and unmet need for family planning between 1990 and 2015: a systematic and comprehensive analysis. Lancet. May 11;381(9878):1642-52. doi: 10.1016/S01406736(12)62204-1. Epub 2013 Mar 12. PMID: 23489750.

American Society for Reproductive Medicine (2012). Age and Fertility. A Guide for Patients. Revised 2012, 1-15

Avogo, W., Agadjanian, V., \& Casterline, J. B. (2008). Social interaction, fertility intentions and male involvement in fertility decline in SubSaharan Africa: Longitudinal evidence from Ghana.

Cleland, J., Bernstein, S., Faundes, A., Glasier, A., \& Innis, J. (2006). Family planning: The unfinished agenda. The Lancet (368), 18101827.

Colleran, H., \& Mace, R. (2015). Social network- and community-level influences on contraceptive use: evidence from rural Poland. Proceedings.

Biological sciences, 282(1807), 20150398 https://doi.org/10.1098/rspb.2015.0398

Davanzo,J., Hale, L., Razzaque, A and Rahman, $M(2008)$ The effects of pregnancy spacing on infant and child mortality in Matlab, Bangladesh: How they vary by the type of pregnancy outcome that began the interval, Population Studies, 62:2, 131154,DOI: 10.1080/00324720802022089

Ernest, A., Saiteu, G., \& Maro, O. (2011). Promoting Modern Family Planning among Tanzania's nomadic Communities. Retrieved on 12th May, 2012 from www.kit.nl/net/KIT.

Garson, D. (2012). Sampling. North Caroline State University School of Public and International Affairs, Statistical Associates Publishing, Blue Book Series.

Gold, J., Pedrana, A.E., Sacks-Davis, R. (2011). A systematic examination of the use of Online social networking sites for sexual health promotion. BMC Public Health 11, 583 https://doi.org/10.1186/1471-2458-11-583
Jupp, V. (2006). Purposive Sampling. The SAGE Dictionary of Social Research Methods.

Kaplan, J. (2013). Multstage sampling/evaluation. Retrieved from betterevaluation. org/evaluation-options/multistage.

Kodz, I. A. (2009). Three essays on the fertility preferences of rural Ghanaian women. A longitudinal perspective. A Dissertation in Sociology and Demography. The Pennsylvania State University. The Graduate School Department of Socology.

Mosha, H and Ruben R (2013) Communication, knowledge, social network and family planning utilization among couples in Mwanza, Tanzania. African Journal of Reproductive Health 17(3),57-69.

Rossier, C., and Bernardi, L. (2010). Social interaction effects on fertility: Intentions and Behaviours. European Journal of Population, 25, 467-485.

Rustagi, N., Taneja, D. K., Kaur, R., \& Ingle, G. K. (2010). Perspectives and Issues, Health and Population , 33(1), 10-15.

Samandari, G., Speizer, I. S., \& O'Connell, K. (2010).The role of social support and parity in contraceptive use in Cambodia. International Perspectives on Sexual and Reproductive Health 36 (3), 122-131.

Sarfraz, M., Hamid, S., Rawstorne, P. (2021). Role of social network in decision making for increasing uptake and continuing use of long acting reversible (LARC) methods in Pakistan. Journal of Reproductive Health Vol.18, 96 https://doi.org/10. 1186/s 12978-021-01149-0.

Sharan, M and Valente, T (2002). Spousal Communication and Family Planning Adoption: Effects of a Radio Drama Serial in Nepal. International perspectives on sexual and reproductive health. A Journal of peer reviewed research, 28(1),16-25

Taherdoost, H. (2016). Sampling Methods in Research Methodology; How to Choose a Sampling Tech- nique for Research. International Journal of Academic Research in Management 5 (2), 18-27. 
Tavakol, M., and Dennick, R. (2011). Making sense of Cronbach's alpha. International Journal of Medical Education, 2, 53-55.

UN (2008). World contraceptive use. UN Department of Economic and Social Affairs, Population Division. Retrieved on 12 May, 2012 from www.un.org/esa/population/ publications/.

UN (2015). Department of Economic and Social Affairs, Population Division (2015). World Contraceptive Use 2015 (POP/D B/CP/Re v2015)

URT (2010). Ministry of health and social welfare. National family planning costed implementation programme 2010-2015. Reproductive and Child Health Section.
USAID (2007). Long Acting and Permanent Methods of Contraception: Meeting Clients Needs. Dar es Salaam: Washington DC.

Yeakey, M., Chipeta, E., Taulo, F and Amy O. Tsui (2009). The lived experience of Malawian women with obstetric fistula, Culture, Health \& Sexuality, 11:5, 499-513, DOI: 10.1080/13 691050902874777.

Yee, $\mathrm{L}$ and Simon, M (2010). The Role of the Social Network in Contraceptive Decision-making Among Young, African American and Latina Women Journal of Adolescent Health 47(4):374-80 DOI: 10.1016/j.ja dohe alth.2010.03.014 